\title{
Supplements of
}

\section{Fluorescent biological aerosol particles over the central Pacific Ocean:}

covariation with ocean-surface biological activity indicators

Kaori Kawana $^{1}$, Kazuhiko Matsumoto ${ }^{1}$, Fumikazu Taketani ${ }^{1}$, Takuma Miyakawa ${ }^{1}$, Yugo Kanaya ${ }^{1}$

${ }^{1}$ Earth Surface System Research Center, Research Institute for Global Change, Japan Agency for Marine-Earth Science and Technology (JAMSTEC), Yokohama, 2360001, Japan

Correspondence to: Kaori Kawana (kawanak@jamstec.go.jp) 
Table S1. List of seawater sampling date and location.

\begin{tabular}{cccc}
\hline Date (UTC) & Latitude & Longitude & Zone \\
\hline $2019 / 03 / 0900: 55$ & $6.35^{\circ} \mathrm{S}$ & $161.41^{\circ} \mathrm{W}$ & $\mathrm{EQ}$ \\
$2019 / 03 / 0919: 58$ & $3.53^{\circ} \mathrm{S}$ & $164.39^{\circ} \mathrm{W}$ & $\mathrm{EQ}$ \\
$2019 / 03 / 1022: 56$ & $0.00^{\circ} \mathrm{S}$ & $168.56^{\circ} \mathrm{W}$ & $\mathrm{EQ}$ \\
$2019 / 03 / 1120: 00$ & $2.54^{\circ} \mathrm{N}$ & $172.08^{\circ} \mathrm{W}$ & $\mathrm{EQ}$ \\
$2019 / 03 / 1219: 56$ & $6.05^{\circ} \mathrm{N}$ & $175.39^{\circ} \mathrm{W}$ & $\mathrm{EQ}$ \\
$2019 / 03 / 1320: 56$ & $9.25^{\circ} \mathrm{N}$ & $179.21^{\circ} \mathrm{W}$ & $\mathrm{EQ}$ \\
$2019 / 03 / 1420: 59$ & $13.00^{\circ} \mathrm{N}$ & $177.21^{\circ} \mathrm{E}$ & $\mathrm{NP}$ \\
$2019 / 03 / 1520: 58$ & $16.43^{\circ} \mathrm{N}$ & $174.04^{\circ} \mathrm{E}$ & $\mathrm{NP}$ \\
$2019 / 03 / 1620: 59$ & $20.35^{\circ} \mathrm{N}$ & $170.35^{\circ} \mathrm{E}$ & $\mathrm{NP}$ \\
$2019 / 03 / 1722: 00$ & $23.17^{\circ} \mathrm{N}$ & $165.55^{\circ} \mathrm{E}$ & $\mathrm{NP}$ \\
$2019 / 03 / 1821: 58$ & $24.30^{\circ} \mathrm{N}$ & $160.45^{\circ} \mathrm{E}$ & $\mathrm{NP}$ \\
$2019 / 03 / 1921: 58$ & $25.42^{\circ} \mathrm{N}$ & $155.38^{\circ} \mathrm{E}$ & $\mathrm{NP}$ \\
$2019 / 03 / 2022: 56$ & $27.00^{\circ} \mathrm{N}$ & $150.00^{\circ} \mathrm{E}$ & $\mathrm{NP}$ \\
$2019 / 03 / 2123: 59$ & $30.56^{\circ} \mathrm{N}$ & $146.01^{\circ} \mathrm{E}$ & $\mathrm{KR}$ \\
$2019 / 03 / 2210: 24$ & $32.25^{\circ} \mathrm{N}$ & $144.37^{\circ} \mathrm{E}$ & $\mathrm{KR}$ \\
\hline
\end{tabular}



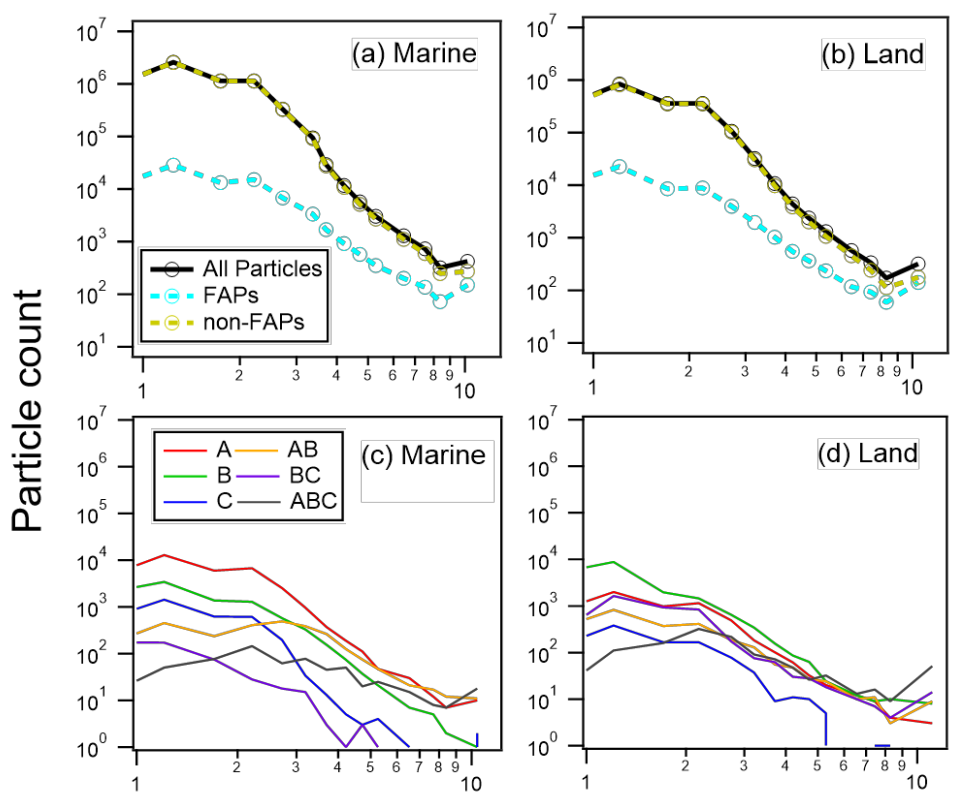

Optical Diameter $(\mu \mathrm{m})$

Figure S1. Count of all particles (black line), fluorescent aerosol particles (FAPs, light blue line), and non-FAPs (light green

5 line) obtained by WIBS-4A during (a) Period 1 when oceanic air masses were dominant, and (b) Period 2 when the influence of terrestrial air masses was prominent. Count of particles with different types of FAPs during (c) Period 1, and (d) Period 2. 

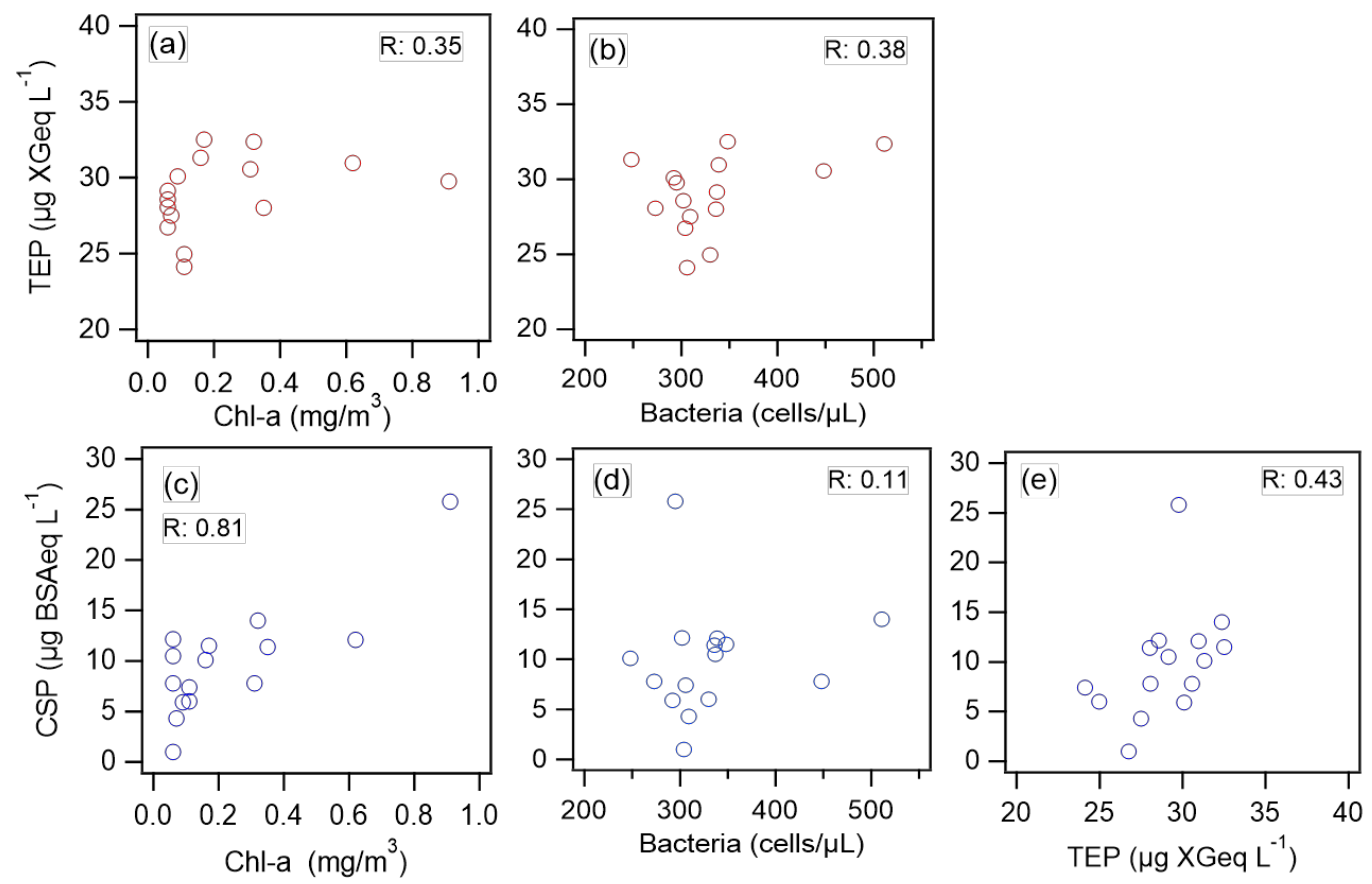

Figure S2. Correlations between concentrations of bioindicator and/or biological particles concentration for sampled seawater:

5 (a) TEPs and Chl-a, (b) TEPs and bacteria, (c) CSPs and Chl- $a$, (d) CSPs and bacteria, and (e) CSPs and TEPs. 

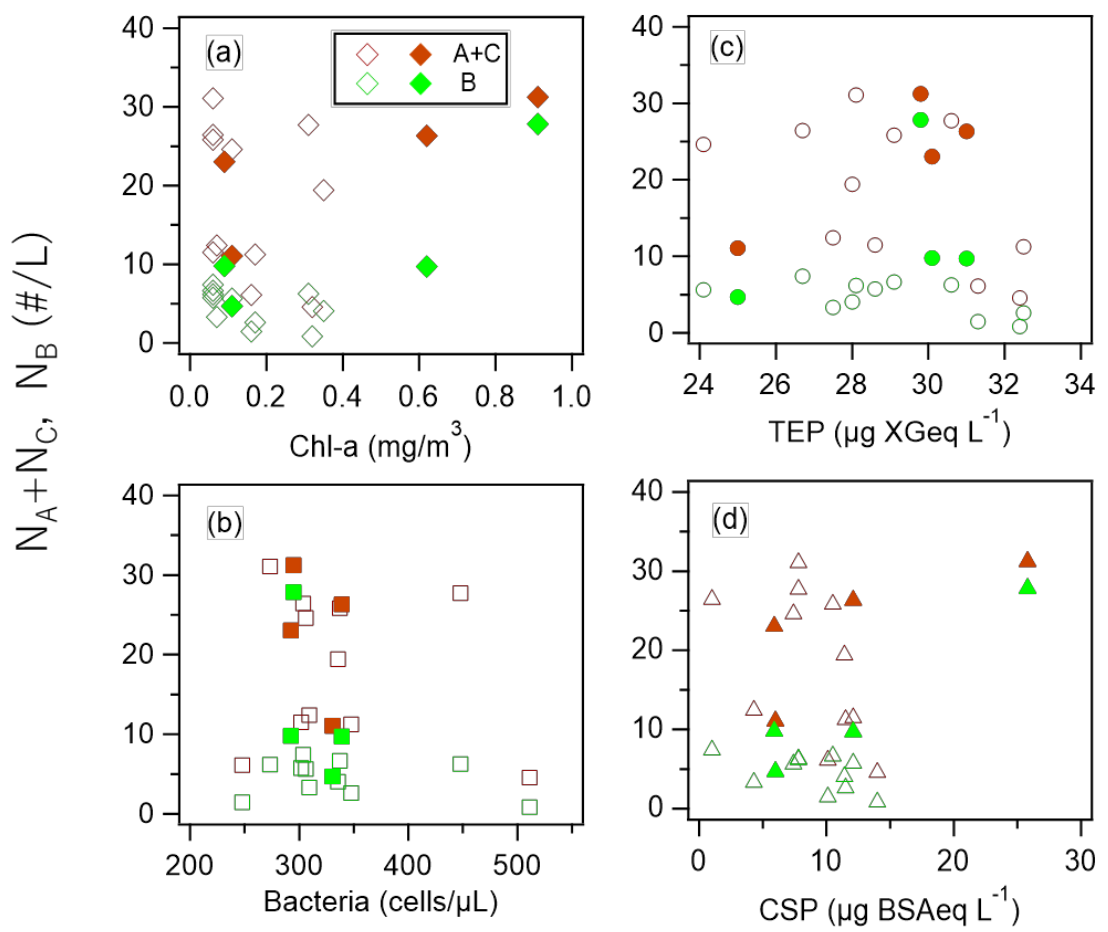

Figure S3. (a)-(d) Same as Figs.8c-8f, but for bioindicators only. 

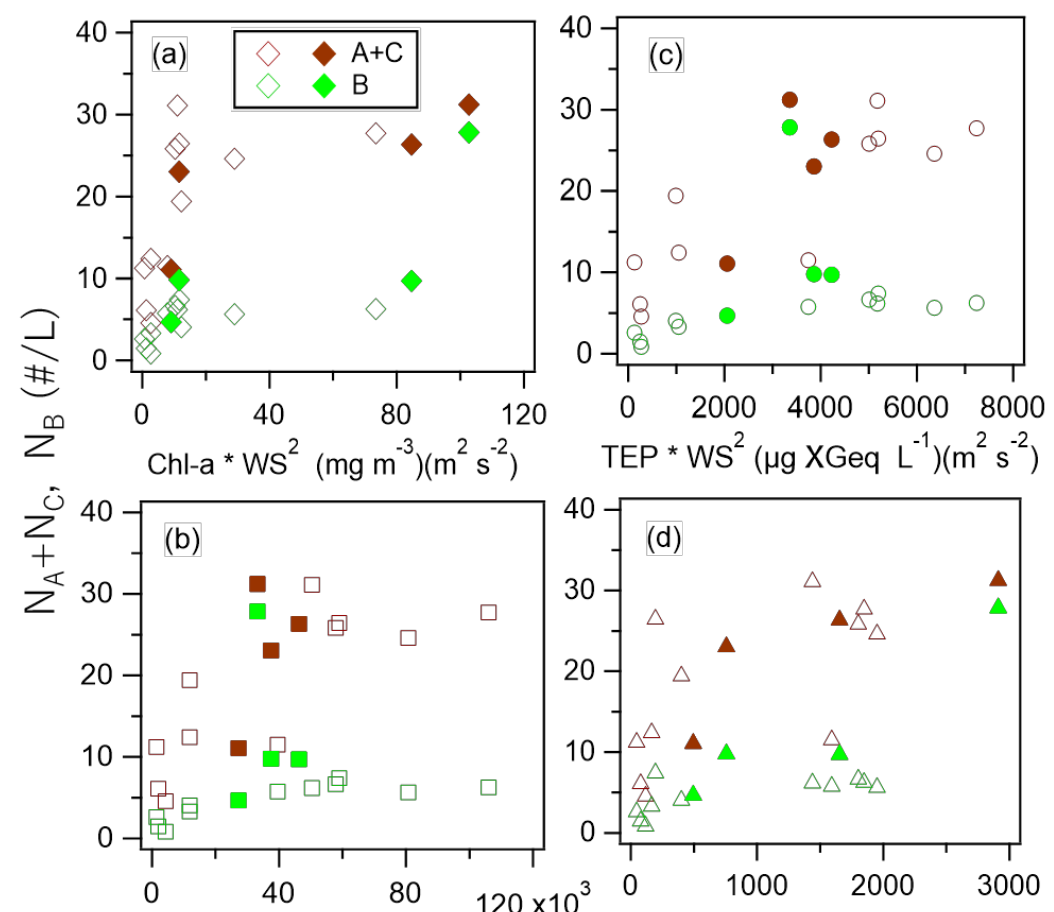

Bacteria * $W S^{2}\left(\right.$ cells $\left.\mu L^{-1}\right)\left(m^{2} s^{-2}\right) \quad C S P * W s^{2}\left(\mu g\right.$ BSAeq $\left.L^{-1}\right)\left(m^{2} s^{-2}\right)$

Figure S4. (a)-(d) Same as Figs.8c-8f, but with an exponent of 2 for wind speed. 


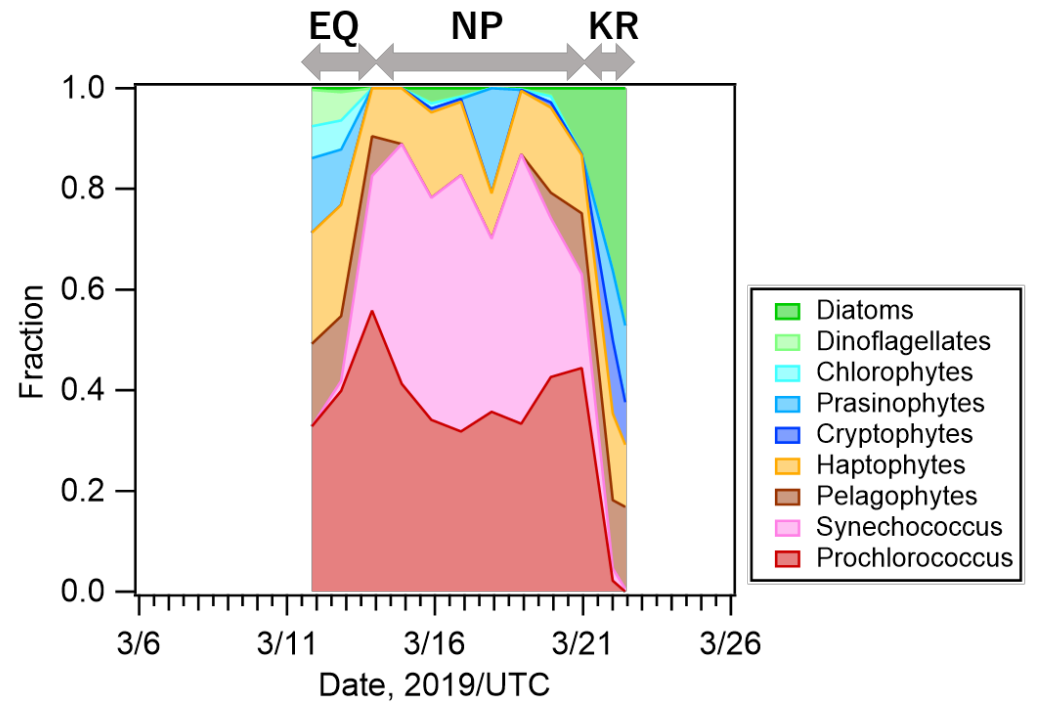

Figure S5. Distribution of phytoplankton species in the surface seawater. 